\title{
Vasectomies of male African elephants as a population management tool: A case study
}

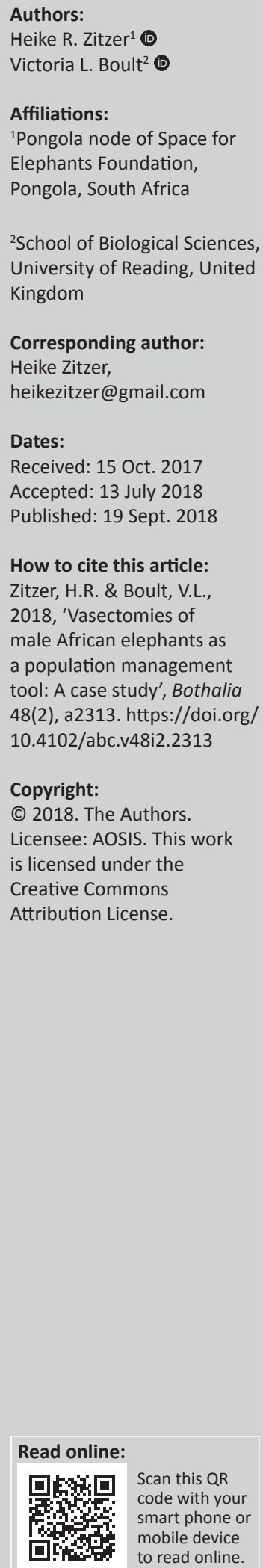

Elephant populations in South Africa are largely confined to fenced reserves and therefore require continued management to prevent high elephant densities that may cause habitat degradation. Growing human populations surrounding these reserves limit the possibility for wildlife range expansion, adding socio-economic considerations to the growing list of challenges reserve managers must contend with. Often, reserves have therefore opted to manage elephant population growth using various contraceptive methods to reduce birth rates, with lethal control acting as a last resort.

Reserve owners at the Pongola Game Reserve South in northern KwaZulu-Natal opted to vasectomise the oldest male elephants to limit elephant population growth. Besides the reduction in birth rates, vasectomies were anticipated to have minimal impacts on behaviour. This study aimed to examine behavioural implications of treatment by monitoring musth, dominance and social behaviours of vasectomised males.

Physical and behavioural observations of vasectomised males were recorded using instantaneous scan sampling and continuous focal samples of study individuals between 2011 and 2016. These data were also collected for non-treated adolescent males, with which to substantiate potential impacts of vasectomies.

This case study has revealed that the behaviour of the vasectomised males was not influenced by vasectomies: musth was displayed as anticipated in the oldest males; a linear dominance hierarchy was maintained, headed by the oldest individual, and association patterns with female groups remained intact. Further, the younger non-treated males fell in line with the overall dominance hierarchy.

This unique post-treatment study supports the use of vasectomies as a relatively cost-effective (one-off treatment), low-risk and successful tool for the management of elephant population growth, and an option which is preferable to both lethal control and hormonal contraceptives. Further research to establish the impacts of vasectomies on female behaviour and population dynamics is recommended.

\section{Introduction}

Across most of Africa, elephants are increasingly losing the competition for space with a burgeoning human population over the past decades (Parker \& Graham 1989). There are large disparities between African elephant (Loxodonta africana) range states in terms of population trends and management approaches. In East Africa, elephants still range beyond reserve boundaries and travel historical migration paths (Chase et al. 2016); however, with a growing human population and the associated conversion of elephant habitats into human-dominated landscapes, the management of elephants in East Africa could move towards the southern African model, where elephant populations become confined to small fenced reserves, unable to migrate and kept at increasingly high densities.

Elephant populations in many of these southern African reserves are growing and have attained densities higher than previously thought possible. Such irruptive growth (Mackey et al. 2009) has sparked concerns that high elephant densities may have negative impacts on vegetation (Slater 2012), and thus elephant population control has become a necessary practice for reserve managers. Increasing human populations leave little or no opportunity for reserve expansion, and so attention has turned to reducing or limiting elephant population growth within reserves.

Over the last four decades, several population control methods have been used (Rubio-Martínez et al. 2014) of which culling resulted in rapid reduction in elephant numbers (Whyte 2001); but, owing to ethical considerations, negative publicity and consequential destabilisation of elephant 
behaviour and population dynamics, culling was discontinued in the mid-1990s in South Africa (Rubio-Martínez et al. 2014). In the years following, various management tools were trialled, studied and became available to limit growing elephant populations in these confined reserves. These included the translocations of elephant herds, bond groups and mature adult males to other conservation areas and reserves that could accommodate them; the creation of wildlife corridors thereby linking one or more reserves; and the use of available contraception and sterilisation methods for both male and female elephants. Lethal control (i.e. culling) remains the last resort management tool for immediate reduction of elephant numbers if all other attempts fail (Lötter et al. 2008). As stated earlier, range expansion via corridors is near impossible because of human-dominated landscapes interspersing reserves. The effectiveness of translocations has also proven only a short-term solution as elephant populations in the source reserve soon recover and could result in another reserve with high elephant densities. Translocations are also hugely costly (Hofmeyr 2003). Focus has therefore turned to contraceptive and sterilisation techniques, several of which have been utilised in elephants: porcine zona pellucida (pZP) immunocontraception of female elephants; laparoscopic vasectomies of male elephants; injection of gonadotropinreleasing hormone (GnRH vaccine) suppressant of elephants (also predominantly used to supress aggression associated with musth), for male and female elephants.

Porcine zona pellucida is applied to female elephants and works by preventing sperm from fertilising the egg during mating (Fayrer-Hosken et al. 2000), while GnRH is used to prevent sperm development and limits the secretion of testosterone in male elephants (Brown et al. 1993) and prevents follicle development and ovulation in female elephants (Valades et al. 2012). Both of these treatments require regular boosters to maintain their contraceptive ability. Treatment of females with pZP or GnRH also requires that a large proportion of breeding females be treated to significantly reduce population growth, because female numbers are closely related to population size (Clutton-Brock et al. 1997). These treatments are therefore time-consuming and require ongoing costs, with the added concern that regular treatment could cause high levels of stress in populations and may result in negative elephant behaviours towards people or vehicles. In addition, GnRH has been observed to alter male elephant behaviour including a reduction in dominance status and a reduction in the occurrence of musth (De Nys et al. 2010; Doughty et al. 2014).

Vasectomies overcome many of the issues associated with hormonal treatments. First used in elephants in 2004, the vasectomy procedure was initially lengthy (taking over $4 \mathrm{~h}$ ), required a specialist team of vets and resulted in complications causing the death of one individual (Marais et al. 2013). However, with increasing efficiencies and training, each procedure now takes less than an hour allowing up to three bulls to be vasectomised in a day, has been performed by local South African vets and rarely results in complications
(Elephant Population Management Project 2010). The procedure is a one-off operation in which a section of the vas deferens is removed via laparoscopic techniques (Elephant Population Management Project 2010; Rubio-Martínez et al. 2014), removing the need for repeated treatments, preventing ongoing costs and reducing stress for the treated individual (Bokhout, Nabuurs \& De Jong 2005). It is also expected that elephant behaviour remains unchanged as a result of vasectomies because the testes and associated tissues remain and maintain hormonal function (Bokhout et al. 2005). However, this assumption has not yet been tested scientifically and as such is the focus of this article.

We examine the behavioural implications of vasectomies in terms of musth behaviour, dominance hierarchies and association patterns of male elephants. Musth is a physiological and behavioural condition exclusive to male elephants, which is manifested by bouts of elevated testosterone, aggression and heightened sexual activity (Hollister-Smith et al. 2007). Musth is an important aspect of male elephant society as musth in older, dominant males suppresses musth in younger males, maintaining discipline in elephant society (Archie et al. 2006; Hollister-Smith et al. 2007; Poole 1989; Wittemeyer \& Getz 2007). In turn, dominance hierarchies in elephants are strongly linear to ensure that only the oldest, most dominant males with the best genes gain access to receptive females, maintaining the fitness of the population as a whole (Clutton-Brock 1988). Mature males are therefore expected to spend time with female groups when females are receptive, but increasingly spend less time with their natal herd as they mature, spending more time alone or in same-sex associations (Evans \& Harris 2008). It was deemed that examination of these aspects of male behaviour would provide good insight into the behavioural and societal implications of vasectomies with the expectation that natural patterns were maintained.

\section{Research methods and design Case study setting and history}

Pongola Game Reserve South (PGR-S) is a small ( 10 000 hectares; Van Os \& Vos 2000), fenced reserve situated in northern KwaZulu-Natal, south and southwest of Golela/ Swaziland, between the towns of Pongola and Mkuze along the Pongolapoort Dam (Lake Jozini). This dam is centrally situated and surrounded by adjoining private and provincial reserves with the Pongola River feeding into it from the west (Figure 1). Pongola Game Reserve itself runs along the dam's western and short south-eastern natural boundary with a perimeter fence enclosing its outer, western boundary along the N2 National Road and the dammed river enclosing it at its north to northwestern boundary. Fluctuating weather patterns, the annual water release programme of the Pongolapoort Dam, the seasonal flood flow of the Pongola River and water extraction for irrigation and human settlements all contribute to fluctuating increases and decreases of PGR-S's land mass along the shoreline. The climate is hot and semi-arid: the mean annual temperature of the region varies from $20.7^{\circ} \mathrm{C}$ to $23^{\circ} \mathrm{C}$ (Van Rooyen \& Van Rooyen 2008) with an average annual rainfall of $543 \mathrm{~mm}$. 


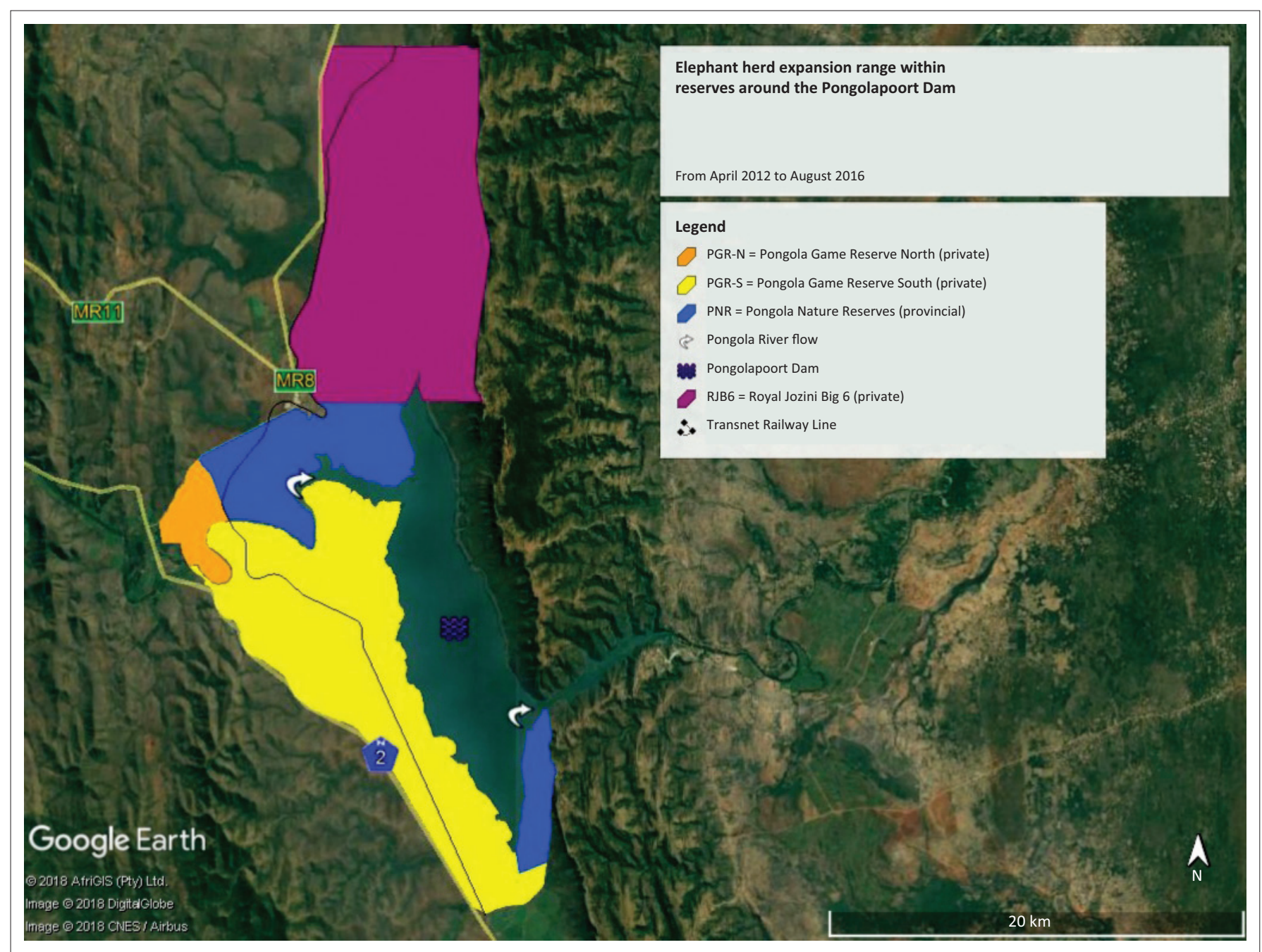

$\mathrm{km}$, kilometres.

FIGURE 1: Case study setting and historical elephant herd expansion range from 2012 to 2016.

The elephant population of PGR-S descends from two family groups translocated from the Kruger National Park (KNP) to PGR-S in 1997, three adult males introduced from KNP during 1998, three adult male escapees arriving in 2002 and five orphan elephants (four females and one male), which were guided by the PGR-S's resident elephant male into the reserve in 2000. The current population consists of about 84 individuals in two distinct herds, namely the A\&B Family Herd ( 53 individuals) and the Orphan's Family Herd (20 individuals) and males consisting of seven vasectomised young adults and four non-treated adolescents (Appendix 1). Beginning in 2012, the elephants started moving around fence boundaries in the waters of the Pongolapoort Dam onto adjoining reserves. As of 2016, the elephant movement range covered an area of about 27400 hectares encompassing almost the entire Pongolapoort Dam (Figure 1).

\section{Vasectomy procedure}

In 2008, in-field vasectomies were carried out on seven adolescent male elephants in PGR-S to limit its growing elephant population. The nine oldest males (aged 9-55 years) were identified as possible vasectomy candidates, only seven of which (aged 9-18 years) were vasectomised; the oldest male (age 55) was not vasectomised because of fears that he may not be strong enough to survive the procedure; the procedure was attempted on the second oldest male (aged between 40 and 45 years), but was unsuccessful because of large fat deposits around his testes which prevented the surgeons from finding the vas deferens duct in the $1 \mathrm{~h}$ time frame allowed for the general anaesthesia. Instead, both males were treated with the hormonal contraceptive GnRH vaccine (Improvac ${ }^{\circledR}$ ) to stop further population growth. These males received $\mathrm{GnRH}$ treatment from October 2009 and November 2008, respectively. The oldest male was removed from the reserve in May 2010. The second oldest male's reaction to the administration of GnRH produced mixed results, with success dependent on the regularity and dosage administered, which varied because of logistical and practical limitations. This male was removed from the reserve in August 2013. Vasectomies and initial subsequent monitoring were funded by Disney's Animal Programmes. Further monitoring was established by the Elephant Population Management Programme (EPMP) created in 2009-2010 (Zuba 2017). 


\section{Behavioural data collection}

Regular elephant monitoring took place from February 2011 to August 2016. To aid with monitoring, six of the seven vasectomised males (excluding the youngest, MG) were fitted with very high frequency (VHF) radio collars, and daily telemetry signals were used to locate the collared individuals.

Altmann's (1974) sampling method was applied using instantaneous 30 -min scan samples followed by 15-min focal samples between successive scan samples, unless no elephants were visible at the time of scan sampling. Instantaneous scan samples included the recording of positional data, the date, time, individual elephant(s) and the total number of individuals present, their behaviour displayed at the time, as well as the vegetation type and dominant vegetation species. Between successive scan samples, 15-min focal samples of a chosen focal individual were collected to record continuously behaviours and interactions (including its associations with other elephants) during this time. Where dominance behaviours were observed, the actor, recipient, winner and loser of the interaction were recorded (Altmann 1974). The scan data were subsequently analysed to determine the association patterns of the study males, while focal data were used to analyse the male dominance hierarchy (Doughty et al. 2014). Physical and behavioural musth signs were recorded whenever observed (Appendix 2).

The resulting 7291 scans and 4340 focal animal samples translated to $911 \mathrm{~h}$ and $56 \mathrm{~min}$ of data accumulated over 6 years (Table 1). Of this time, $730 \mathrm{~h}$ and $8 \mathrm{~min}$ was collected on the seven vasectomised and the four non-treated adolescent males, and $181 \mathrm{~h}$ and $48 \mathrm{~min}$ was collected on the adult females (Table 1).

\section{Male dominance}

Accurate testing for linearity in a male dominance hierarchy requires regular data collection, ensuring equal amounts of data are collected on each of the study males. Dominance interactions and their outcomes were incorporated into

TABLE 1: Focal animal samples of the study males and all study females combined collected from February 2011 to August 2016.

\begin{tabular}{lcl}
\hline Individuals or group & $\begin{array}{c}\text { Total number of } \\
\text { focal samples }\end{array}$ & $\begin{array}{l}\text { Total observation } \\
\text { time (hh:mm:ss) }\end{array}$ \\
\hline SH (vasectomised) & 491 & $107: 30: 03$ \\
KO (vasectomised) & 490 & $106: 03: 26$ \\
LU (vasectomised) & 319 & $69: 08: 57$ \\
AS (vasectomised) & 358 & $74: 59: 14$ \\
KH (vasectomised) & 469 & $100: 41: 53$ \\
NT (vasectomised) & 477 & $104: 12: 10$ \\
MG (vasectomised) & 279 & $58: 59: 34$ \\
SM2 (non-treated) & 186 & $38: 25: 34$ \\
SM3 (non-treated) & 256 & $53: 44: 28$ \\
SM4 (non-treated) & 31 & $5: 53: 16$ \\
UM (non-treated) & 55 & $10: 29: 43$ \\
Adult females (breeding) & 929 & $181: 48: 07$ \\
\hline Total & 4340 & $\mathbf{9 1 1 : 5 6 : 2 5}$ \\
\hline Males only & $\mathbf{3 4 1 1}$ & $\mathbf{7 3 0 : 0 8 : 1 8}$ \\
\hline
\end{tabular}

hh:mm:ss, hours, minutes, seconds. two separate dominance matrices using Appleby's method (1983) to test the strength of the hierarchy. Matrix 1 contained the vasectomised males only $(n=7)$; matrix 2 included the four additional non-treated males $(n=11)$. Matrices were constructed by scoring ' 1 ' where an individual dominated another, and ' 0 ' where the individual was dominated by another or where no interaction was observed, or ' $0.5^{\prime}$ ' for both individuals where the relationship could not be established (Doughty et al. 2014; Appendix 3-5). Thereafter, the same male groups were tested for linearity by applying Landau's linearity index (h) (1951). The formula of Landau's linearity index is:

$h=\left(\frac{12}{n^{2}-n}\right) \sum_{a=1}^{n}\left[v_{a}-\frac{(n-1)}{2}\right]^{2}$

where $n$ equals the number of individuals, $a$ equals 1 for an individual that has dominated another and $v_{a}$ equals the number of individuals that were dominated by $a$.

Interpretation of Landau's linearity index is (De Vries 1995):

$h=0 \quad$ indicates no hierarchy.

$h=0.5+\quad$ indicates a linear yet changeable hierarchy.

$h=1 \quad$ indicates a completely linear hierarchy.

\section{Male association patterns}

Association patterns were recorded to establish any behavioural changes that may have taken place since the vasectomies. The descriptions of Slater and Knights (2011) were followed. These included calculating the mean percentage of observation time $( \pm$ SEM) that each vasectomised male and each non-treated male spent either alone, in same-sex (males only) groups and in mixed-sex groups (groups comprising at least one male and one female).

\section{Ethical considerations}

Intense and regular elephant monitoring and subsequent research was carried out during 6-8 h daily, thereby allowing the elephants to become comfortable with the research monitor's constant presence. The same monitoring vehicle was used, and appropriate distances from the elephants were constantly kept with the intention of causing minimal disturbance to and change in behaviour of the elephant. This procedure was followed throughout all years by strict adherence to the guidelines outlined within 'The comfort zones and personal space of animals' supplied by Space for Elephants Foundation and the guiding principles outlined within the National Norms and Standards for the Management of Elephants in South Africa (Department of Environmental Affairs and Tourism 2008).

\section{Data protection}

Owners and managers of the private PGR and Royal Jozini Big 6 Estate, members of Space for Elephants Foundation and the Elephant Population Management Programme, elephant conservation management bodies of Ezemvelo KwaZuluNatal Wildlife and interested research parties received regular 
elephant reports covering elephant events, including research analysis and results. Management of Operation Wallacea and Wildlife \& Ecological Investments companies and their students had access to the research database on a yearly basis to further general elephant and post-vasectomy research efforts and contribute to the elephant management efforts in their greater habitat of the Pongolapoort and in other reserves.

\section{Results}

\section{Vasectomised male musth status}

Five of the seven vasectomised males have experienced musth in varying degrees including full musth status. Observed musth is signified by physical and behavioural signs in these individuals that include, physically, copious temporal gland secretions, swollen temporal glands, a discoloured penis sheath and urine dribbling, and, behaviourally, indecisive movement, individual ear flap and musth walk. Given the age of the vasectomised males, first musth signs were experienced at a younger age than expected in natural populations.

\section{Male dominance hierarchy}

The result of Landau's linearity index to test for linearity in the dominance hierarchy of the seven vasectomised males revealed that ' $h=1$ ', confirming that there is a complete linearity in the dominance hierarchy as expected for the natural age-structured dominance hierarchies observed in male elephants. When the additional non-treated males were included in the dominance hierarchy, Landau's linearity index resulted in ' $h$ ' equals ' 0.95 ', again confirming strong, age-structured linearity in the dominance hierarchy with the younger, non-treated males at the bottom end of the dominance hierarchy as expected in a natural male dominance hierarchy.

\section{Male association patterns}

Results (Table 2) indicated that all males spent the majority of time in mixed-sex groups. Older, vasectomised males spent a fairly even amount of time alone as in same-sex groups. The four non-treated males spent large proportions of their time

TABLE 2: The mean percentage of observation time each vasectomised and nontreated male spent alone, in same-sex groups (with other males but neither of the female groups) and in mixed-sex groups (with one or more of the female groups).

\begin{tabular}{lcccc}
\hline Male ID $(\boldsymbol{n}=\mathbf{1 1})$ & $\begin{array}{c}\text { Age } \\
\text { (years in 2016) }\end{array}$ & $\begin{array}{c}\text { Alone } \\
( \pm \mathrm{SEM})\end{array}$ & $\begin{array}{c}\text { Same-sex } \\
( \pm \mathrm{SEM})\end{array}$ & $\begin{array}{c}\text { Mixed-sex } \\
( \pm \mathrm{SEM})\end{array}$ \\
\hline SH (vasectomised) & 25 & 26.83 & 24.25 & 48.92 \\
KO (vasectomised) & 21 & 21.40 & 33.85 & 44.76 \\
LU (vasectomised) & 20 & 28.26 & 26.14 & 45.60 \\
AS (vasectomised) & 19 & 36.80 & 19.10 & 44.10 \\
KH (vasectomised) & 19 & 2.03 & 18.70 & 79.28 \\
NT (vasectomised) & 19 & 18.94 & 26.50 & 54.56 \\
MG (vasectomised) & 17 & 19.04 & 27.31 & 53.65 \\
SM2 (non-treated) & $15 \pm$ & 3.60 & 38.43 & 57.97 \\
SM3 (non-treated) & $14 \pm$ & 3.43 & 13.71 & 82.85 \\
SM4 (non-treated) & $12 \pm$ & 8.74 & 18.20 & 73.06 \\
UM (non-treated) & 12 & 17.39 & 15.13 & 67.48 \\
\hline
\end{tabular}

Note: $n=11$, the number of study males.

\pm SEM, the mean percentage of observation time spent. in mixed-sex groups, often with their natal herd (Appendix 6), and were rarely observed alone; preferring the company of group situations. The time spent in same-sex groups was close to that seen in the older vasectomised males, suggesting an increasing transition into maturity. SM2 spent the least time of all non-treated males in mixed-sex groups and the most time in same-sex groups indicative of his older age and rising maturity level above other non-treated adolescent males. UM was the most independent of the non-treated males, but not quite at the same maturity level as SM2, owing to more time spent in mixed-sex groups. These overall association behaviours of all vasectomised and non-treated males also proved to follow natural male associations that conformed to their respective age categories.

\section{Discussion}

The PGR-S case study has presented a unique opportunity to monitor the physical and behavioural implications of vasectomies in wild male African elephants. The resulting observations have provided crucial information required by veterinarians and wildlife authorities to make appropriate management decisions, lacking from the current literature.

Physical and behavioural signs of musth were observed in most of the vasectomised males following treatment in 2008. This indicates that while vasectomies inhibit successful reproduction, the hormonal functions of the testes are maintained, causing vasectomised males to enter musth as expected in non-treated elephants. This is in contrast with hormonal contraceptives such as $\mathrm{GnRH}$, which are used often in captive elephants to suppress musth and can have similar effects on wild elephants (De Nys et al. 2010). However, musth is important for the maintenance of elephant society, with older musth males suppressing musth in younger males and preventing 'delinquent' behaviours observed in some young male elephants without the presence of an older musth male (e.g. Pilanesburg; Slotow et al. 2000; Slotow \& van Dyk 2001). The young age of the vasectomised males displaying musth signs is unlikely to be as a result of vasectomies and rather because of the fact that old, dominant bulls (older than 30 years old) were not present or were receiving GnRH treatment during the study period, and as such did not act to suppress musth in these younger individuals. Alternatively, because of measures to cap the population resulting in low female reproductive rates, it may be that constant oestrus cycling in females triggered the vasectomised males to enter musth at an early age. No musth signs were displayed in either of the younger, vasectomised males NT and MG, nor in the four non-treated adolescent males SM2, SM3, SM4 and UM during the study period, as expected for their age, suggesting that the older vasectomised males are still managing to suppress musth in adolescent males.

Dominance hierarchies followed the age-structured linear pattern expected in male elephant societies, with the oldest and thus biggest individuals being most dominant. The dominance hierarchy is maintained even when the non-treated males are included, further confirming that vasectomies do 
not alter the physical or behavioural traits of male elephants nor the resulting male society. Again this is in contrast with GnRH treatment, which has been observed to alter dominance hierarchies in male elephants (Doughty et al. 2014) and is important because naturally, dominant males are afforded best access to females and thus have the best chance of breeding success, by excluding access to females by young males. This has the potential therefore to continue to limit population growth even as younger males age and mature, because dominant males continue to prevent younger, less dominant males from breeding with receptive females.

Association patterns of vasectomised male elephants also show no effect of the treatment. Vasectomised males split their time between mixed-sex and same-sex groups, and being alone. Generally, vasectomised males spend around half of their time in mixed-sex groups, associating with females. Adult males usually associate with females when females are in oestrus and receptive to the males' advances (Moss 1983). Given that females are expected to enter oestrus more often in this population because of population management strategies, females probably enter oestrus frequently and thus attract a high level of association from males. Thus, association of vasectomised males with female groups is as anticipated. The non-treated males spend proportionally more time with female groups than the vasectomised males, as would be expected given their age and still transitional stage between living with their natal group and becoming independent (Evans \& Harris 2008).

Overall, results confirm general expectations that vasectomies do not influence male physical or behavioural characteristics. Indeed, males continue to enter musth following treatment, the age-structured dominance hierarchy is maintained and males continue to associate with female groups as in nontreated elephants. Vasectomies when applied to adult males are therefore successful in limiting population growth while crucially maintaining normal male behaviour and society. This presents vasectomies as a resource-effective (individuals only require treatment once), safe (no negative health implications of the treatment) and successful means of limiting elephant population growth in small, isolated elephant populations such as those often found in South Africa. While the costs involved in the vasectomy procedure are not insignificant (South African rand [R]23 700 per elephant in 2013, primarily associated with the costs of the helicopter and anaesthesia; [Hendrickson \& Stetter 2018]) compared to the cost of a single $\mathrm{GnRH}$ treatment (dose of $5 \mathrm{~mL}$ Improvac ${ }^{\circledR} 1000 \mathrm{mg}$ costs $\mathrm{R} 200$ accounting for dose and dart; [Bertschinger 2018]), the commitment required for $\mathrm{GnRH}$ treatment to maintain its contraceptive ability (primary vaccination followed by a booster 4-7 weeks later, then boosters every 5-6 months; [Bertschinger 2018]) requires ongoing finances and resources. In fact, the costs of vasectomies are decreasing because of improved efficiencies in the procedure (especially when treating multiple males in a small area) and strong financial support from non-profit organisations. When considering GnRH treatment to achieve lifetime contraception would require two doses per year for roughly 45 years (duration of sexual maturity in male elephants), the costs of vasectomies and GnRH (R18 000) to limit population growth in the long term are comparable.

Application of vasectomies to larger elephant populations, where it is not feasible to treat all adult males, and in the longer term, as younger males gain age and maturity, will require careful consideration and monitoring, but the results presented here suggest that vasectomising dominant males, who effectively still enter musth and prevent access of younger males to receptive females, presents a promising solution. Further investigation is required, however, to establish the impacts of vasectomies on female behaviours and society; the observed increased occurrence of oestrous cycles and drop in birth rates may influence female behaviour and population dynamics in the longer term. The absence of mature males and the observed earlier onset of musth in adolescent and young adult males also deserve further attention. However, this article presents the only longrunning, continuous post-vasectomy study in wild African elephants, the results of which are applicable to reserve managers facing high elephant densities across southern Africa and potentially beyond, as elephants are increasingly compressed into smaller and more fragmented pockets of land by growing human populations across the continent.

\section{Conclusion}

This study provides strong evidence that male musth, dominance and association patterns, and resulting behaviour and society are not affected by vasectomies in the medium term. We therefore recommend that vasectomies can be used in similar fenced reserves wishing to limit elephant population growth and that vasectomies are preferable over hormonal contraceptive treatments and lethal control, given that male behaviour is maintained, the procedure is resource-effective (one-off treatment), safe and successful. Further research is required to understand the long-term success of vasectomies and the influence on the behaviour of female elephants and overall population dynamics. This article presents results of interest to reserve managers facing high elephant densities across Africa.

\section{Acknowledgements}

The authors thank the members of Operation Wallacea and Wildlife and Ecological Investments, in particular Dr K. Slater, for introducing them to the scientific method of data collection; H.R. Zitzer's former student and fellow researcher, L. Doughty, for teaching them the basics of scientific data analysis; her former student and fellow researcher, M. Pennington, for his useful suggestions about manuscript writing; her fellow research colleague, A. Schaefer; her close friend, S. Meyer; her mentor, Dr H. Kohrs; the Elephant Population Management Program (EPMP) members, M. Stetter, D. Hendrickson and J. Zuba; and T. Guhrs and B. Schulz for their very useful comments and suggestions on this manuscript. Historical written records prior to June 2009 were available from all previous Pongola 
Game Reserve South elephant monitors and researchers. The ability to conduct elephant monitoring on PGR-S, Pongola Nature Reserves, Pongola Game Reserve North and Royal Jozini Big 6 Estate was highly valued. All assistance is duly acknowledged and appreciated.

\section{Competing interests}

The authors declare that they have no financial or personal relationships that may have inappropriately influenced them in writing this article.

\section{Authors' contributions}

H.R.Z. was the main author who was responsible for the acquisition of in-field data collection, its analysis and interpretation and writing of the manuscript. V.L.B. was the co-author who provided critical support in the scientific writing and revisions of the manuscript.

\section{Funding}

Initial three-year funding, including work materials and equipment, was supplied by Disney's Animal Programmes and the Elephant Population Management Programme (EPMP); major and consecutive funding, including work materials and equipment, for this research was provided by H.R. Zitzer's main employer, Dr H. Kohrs (Pongola node of Space for Elephants Foundation). In-field funding material was supplied by the members of the northern KwaZulu-Natal Honorary Officers Group, in particular, also given by her colleague, J. Toucher. V.L.B. was supported by the Natural Environment Research Council (grant number NE/L002566/1).

\section{References}

Archie, E.A., Moss, C.J. \& Alberts, S.C., 2006, 'The ties that bind: Genetic relatedness predicts the fission and fusion of social groups in wild African elephants', Proceedings of the Royal Society of London B: Biological Sciences 273(1586), 513-522. https://doi.org/10.1098/rspb.2005.3361

Altmann, J., 1974, Observational study of behaviour: Sampling methods, Allee Laboratory of Animal Behaviour, University of Chicago, Chicago, IL.

Appleby, M.C., 1983, The probability of linearity in hierarchies, Sub-department of Animal Behaviour, University of Cambridge, Cambridge.

Bertschinger, H.J., 2018, email, 26 June, henkbert@tiscali.co.za

Bokhout, B., Nabuurs, M. \& De Jong, M., 2005, 'Vasectomy of older bulls to manage elephant overpopulation in Africa: A proposal', Pachyderm 39, 97-103.

Brown, J.L., Bush, M., Wildt, D.E., Raath, J.R., de Vos, V. \& Howard, J., 1993, 'Effects of $\mathrm{GnRH}$ analogues on pituitary-testicular function in free-ranging African elephants (Loxodonta africana)', Journal of Reproduction and Fertility 99(2), 627-634. https://doi.org/10.1530/jrf.0.0990627

Chase, M.J., Schlossberg, S., Griffin, C.R., Bouché, P.J., Djene, S.W., Elkan, P.W. et al., 2016, 'Continent-wide survey reveals massive decline in African savannah elephants', PeerJ 4, p.e2354. https://doi.org/10.7717/peerj.2354

Clutton-Brock, T.H., 1988, Reproductive success: Studies of individual variation in contrasting breeding systems, University of Chicago Press, Chicago, IL.

Clutton-Brock, T.H., Illius, A.W., Wilson, K., Grenfell, B.T., MacColl, A.D.C. \& Albon, S.D., 1997, 'Stability and instability in ungulate populations: An empirical analysis', The American Naturalist 149(2), 195-219. https://doi.org/10.1086/285987

De Nys, H.M., Bertschinger, H.J., Turkstra, J.A., Colenbrander, B., Palme, R. \& Human A.M., 2010, 'Vaccination against GnRH may suppress aggressive behaviour and musth in African elephant (Loxodonta africana) bulls: A pilot study', Journal of the South African Veterinary Association 81(1), 8-15. https://doi.org/10.4102/jsava. v81i1.88
De Vries, H., 1995, 'An improved test of linearity in dominance hierarchies containing unknown or tied relationships', Animal Behaviour 50(5), 1375-1389. https://doi. org/10.1016/0003-3472(95)80053-0

Department of Environmental Affairs and Tourism, 2008, National norms and standards for the management of elephants in South Africa, National Environmental Management: Biodiversity Act, 2004 (Act No. 10 of 2004), Government Gazette, Cape Town, South Africa.

Doughty, L.S., Slater, K, Zitzer, H.R. Avent, T. \& Thompson, S., 2014, 'The impact of male contraception on dominance hierarchy and herd association patterns of African elephants (Loxodonta africana) in a fenced game reserve', Global Ecology African elephants (Loxodonta africana) in a fenced game reserve', Global
and Conservation 2, 88-96. https://doi.org/10.1016/j.gecco.2014.08.004

Elephant Population Management Program, 2010, viewed 27 July 2018 from http:// www.elepmp.org/

Evans, K.E. \& Harris, S., 2008, 'Adolescence in male African elephants, Loxodonto africana, and the importance of sociality', Animal Behaviour 76(3), 779-787. https://doi.org/10.1016/j.anbehav.2008.03.019

Fayrer-Hosken, R.A., Grobler, D., Van Altena, J.J., Bertschinger, H.J. \& Kirkpatrick, J.F. 2000, 'Immunocontraception of African elephants', Nature 407(6801), 149. https://doi.org/10.1038/35025136

Hendrickson, D. \& Stetter, M., 2018, email, 05 July, dean.hendrickson@colostate.edu and mark.stetter@colostate.edu

Hofmeyr, M., 2003. 'Translocation as a management tool for control of elephant populations', paper presented to Proceedings of the first workshop on the control of wild elephant populations, Utrecht University, November 2003.

Hollister-Smith, J.A., Poole, J.H., Archie, E.A., Vance, E.A., Georgiadis, N.J., Moss, C.J. et al., 2007, 'Age, musth and paternity success in wild male African elephants, Loxodonta africana', Science Direct 74(2), 287-296.

Lötter, H.P.P., Henley, M.D., Fakir, S. \& Pickover, M., 2008, 'Ethical considerations in elephant management', in R.J. Scholes \& K.G. Mendell (eds.), Elephant management: A scientific assessment for South Africa, pp. 406-455, Witwatersrand University Press, Johannesburg.

Mackey, R.L., Page, B.R., Grobler, D. \& Slotow, R., 2009, 'Modelling the effectiveness of contraception for controlling introduced populations of elephant in South Africa', Journal of African Ecology 47(4), 747-755. https://doi.org/10.1111/j.13652028.2009.01075.x

Marais, H.J., Hendrickson, D.A., Stetter, M., Zuba, J.R., Penning, M., Siegal-Willott, J. et al., 2013, 'Laparoscopic vasectomy in African savannah elephant (Loxodonta africana); surgical technique and results', Journal of Zoo and Wildlife Medicine 44(4s), S18-S20. https://doi.org/10.1638/1042-7260-44.4S.S18

Moss, C.J., 1983, 'Oestrous behaviour and female choice in the African elephant', Behaviour 86(3), 167-195. https://doi.org/10.1163/156853983X00354

Parker, I.S.C. \& Graham, A.D., 1989, 'Elephant decline (Part I). Downward trends in African elephant distribution and numbers', International Journal of Environmental Studies 34, 287-305. https://doi.org/10.1080/00207238908710539

Poole, J.H., 1989, 'Mate guarding, reproductive success and female choice in African elephants', Animal Behaviour 37, 842-849. https://doi.org/10.1016/0003-3472(89) 90068-7

Rubio-Martínez, L.M., Hendrickson, D.A., Zuba, J.R. \& Marais, H.J., 2014, 'Laparoscopic vasectomy in African elephants (Loxodonta africana)', Veterinary Surgery 43(5), 507-514. https://doi.org/10.1111/j.1532-950X.2014.12163.x

Slater, K., 2012, 'How vasectomy affects elephant behaviour in the longer term', Biodiversity Science, 8, viewed 23 July 2018, from http://www.biodiversityscience. com/2012/12/11/vasectomy-elephant-longer-term/

Slater, K. \& Knights, K., 2011, Recommendations for Elephant Management at Pongola Private Game Reserve, South Africa, Executive summary, Operation Wallacea, Spilsby, UK.

Slotow, R. \& Van Dyk, G., 2001, 'Role of delinquent young "orphan" male elephants in high mortality of white rhinoceros in Pilanesberg National Park, South Africa', Koedoe 44(1), 85-94. https://doi.org/10.4102/koedoe.v44i1.188

Slotow, R., Van Dyk, G., Poole, J., Page, B. \& Klocke, A., 2000, 'Older bull elephants control young males', Nature 408(6811), 425. https://doi.org/10.1038/35044191

Valades, G.B., Ganswindt, A., Annandale, H., Schulman, M.L. \& Bertschinger, H.J., 2012 , 'Non-invasive assessment of the reproductive cycle in free-ranging female African elephants (Loxodonta africana) treated with a gonadotropin-releasing hormone (GnRH) vaccine for inducing anoestrus' Reproductive Biology and Endocrinology 10, 63. https://doi.org/10.1186/1477-7827-10-63

Van Os, R. \& Vos, S., 2000, 'The impact of the African elephant (Loxodonta africana) on the vegetation of Pongola Game Reserve in South Africa', Animal Management, Van Hall Institute, Leeuwarden, Netherlands.

Van Rooyen, N. \& Van Rooyen, M.W., 2008, Vegetation of Phongola Nature Reserve, Ekotrust CC, Pretoria.

Whyte, I.J., 2001, 'Conservation management of the Kruger National Park elephant population', PhD thesis, University of Pretoria, Onderstepoort, South Africa.

Wittemeyer, G. \& Getz, W.M., 2007, 'Hierarchical dominance structure and social organization in African elephants, Loxodonta africana', Animal Behaviour 73, 671-681. https://doi.org/10.1016/j.anbehav.2006.10.008

Zuba, J., 2017, email, 23 October, doczooba@gmail.com 


\section{Appendix 1}

TABLE 1-A1: The Pongolapoort study males' timeline and age-ordered hierarchy set-up descending from the eldest (1) to the youngest (11).

\begin{tabular}{|c|c|c|c|c|c|}
\hline Position in hierarchy & Name or abbreviation & Age (in 2016) & Shoulder height $(\mathrm{cm})$ & Year measured & Treatment \\
\hline 1 & $\mathrm{SH}$ & 25 & 325 & 2013 & Vasectomised \\
\hline 2 & KO & 21 & 319 & 2014 & Vasectomised \\
\hline 3 & $\mathrm{LU}$ & 20 & 276 & 2011 & Vasectomised \\
\hline 4 & AS & 19 & 295 & 2013 & Vasectomised \\
\hline 5 & $\mathrm{KH}$ & 19 & 333 & 2015 & Vasectomised \\
\hline 6 & NT & 19 & 319 & 2015 & Vasectomised \\
\hline 7 & MG & 17 & 240 & 2008 & Vasectomised \\
\hline 8 & SM2 & $15 \pm$ & Not measured & Not measured & Non-treated \\
\hline 9 & SM3 & $14 \pm$ & Not measured & Not measured & Non-treated \\
\hline 10 & SM4 & $12 \pm$ & Not measured & Not measured & Non-treated \\
\hline 11 & UM & 12 & 253 & 2013 & Non-treated \\
\hline
\end{tabular}

$\mathrm{cm}$, centimetres (measurement unit).

\section{Appendix 2}

TABLE 1-A2: In-field ethogram classification used to recognise and record male dominance behaviour between the males as well as physical and behavioural signs of musth.

\begin{tabular}{|c|c|c|c|c|c|c|c|c|c|}
\hline \multirow{2}{*}{\multicolumn{3}{|c|}{$\begin{array}{l}\text { Variable } \\
\text { Male dominance behaviour }\end{array}$}} & \multicolumn{2}{|c|}{ Abbreviation } & \multicolumn{5}{|c|}{ Description } \\
\hline & & & \\
\hline \multicolumn{3}{|l|}{ Chase } & \multicolumn{2}{|l|}{ CS } & \multicolumn{5}{|c|}{ The actor follows the recipient at a $\mathrm{f}$} \\
\hline \multicolumn{3}{|l|}{ Mount } & \multicolumn{2}{|l|}{ MT } & \multicolumn{5}{|c|}{ The actor mounts the recipient. } \\
\hline \multicolumn{3}{|c|}{ Non-physical displacement } & \multicolumn{2}{|l|}{ NPD } & \multicolumn{5}{|c|}{ The actor displaces the recipient by $r$} \\
\hline \multicolumn{3}{|c|}{ Physical displacement } & \multicolumn{2}{|l|}{ PD } & \multicolumn{5}{|c|}{$\begin{array}{l}\text { The actor pushes the recipient using } \\
\text { may move to replace the recipients' }\end{array}$} \\
\hline \multicolumn{3}{|c|}{ Submissive display } & \multicolumn{2}{|l|}{ SD } & \multicolumn{5}{|c|}{$\begin{array}{l}\text { The recipient displays his submission } \\
\text { backward or turning away from the }\end{array}$} \\
\hline \multicolumn{3}{|c|}{ Trunk over body placement } & \multicolumn{2}{|l|}{ TB } & \multicolumn{5}{|c|}{ The actor places his trunk over the re } \\
\hline \multicolumn{3}{|c|}{ Trunk or tusk interlocking } & \multicolumn{2}{|l|}{$\mathrm{TI}$} & \multicolumn{5}{|c|}{$\begin{array}{l}\text { The actor and recipient face each oth } \\
\text { physically attempts to displace the re }\end{array}$} \\
\hline \multicolumn{10}{|c|}{ Male physical and behavioural musth signs } \\
\hline \multicolumn{3}{|c|}{ Discoloured penis sheath } & \multicolumn{2}{|l|}{ DPS } & \multicolumn{5}{|c|}{ Grey to green coloured edge of the $p$} \\
\hline \multicolumn{3}{|c|}{ Indecisive movement } & \multicolumn{2}{|l|}{ IM } & Mov & ment & chan & d frec & uently, is i \\
\hline Individual & ear flap & & IEF & & $\begin{array}{l}\text { The t } \\
\text { secre }\end{array}$ & & mos & $\begin{array}{l}\text { Iy one } \\
\text { cccasic }\end{array}$ & $\begin{array}{l}\text { of the ear } \\
\text { ns the ma }\end{array}$ \\
\hline Musth wal & & & MW & & $\begin{array}{l}\text { The I } \\
\text { with }\end{array}$ & & $\begin{array}{l}\text { eld } h \\
\text { duri }\end{array}$ & $\begin{array}{l}\text { nith } \\
\text { this t }\end{array}$ & $\begin{array}{l}\text { the ears } h \\
\text { ne. His } \mathrm{m}\end{array}$ \\
\hline Swollen te & nporal glands & & STG & & Temp & oral g & nds a & visibl & swollen. \\
\hline Temporal & land secretion & & TGS & & $\begin{array}{l}\text { Temp } \\
\text { a me } \\
\text { othe }\end{array}$ & $\begin{array}{l}\text { pral g } \\
\text { ium s } \\
\text { situat }\end{array}$ & $\begin{array}{l}\text { nd sec } \\
\text { eam ( } \\
\text { ns, th }\end{array}$ & $\begin{array}{l}\text { tions } \\
\text { terme } \\
\text { tis, ne }\end{array}$ & $\begin{array}{l}\text { re presen } \\
\text { liate stage } \\
\text { vousness, }\end{array}$ \\
\hline Urine drib & & & UD & & Cons & ant d & ble o & copior & flow of $s$ \\
\hline Dominan & matrix 1 & & & & & oser & & & \\
\hline Winner & $\begin{array}{l}\text { Vasectomised } \\
\text { males }\end{array}$ & SH & KO & LU & $\mathrm{KH}$ & AS & NT & MG & $\begin{array}{l}\text { Total } \\
\text { wins } \\
\left(v_{a}\right)\end{array}$ \\
\hline & $\mathrm{SH}$ & - & 1 & 1 & 1 & 1 & 1 & 1 & 6 \\
\hline & KO & 0 & - & 1 & 1 & 1 & 1 & 1 & 5 \\
\hline & LU & 0 & 0 & - & 1 & 1 & 1 & 1 & 4 \\
\hline & KH & 0 & 0 & 0 & - & 1 & 1 & 1 & 3 \\
\hline & AS & 0 & 0 & 0 & 0 & - & 1 & 1 & 2 \\
\hline & NT & 0 & 0 & 0 & 0 & 0 & - & 1 & 1 \\
\hline & MG & 0 & 0 & 0 & 0 & 0 & 0 & - & 0 \\
\hline & Total losses & 0 & 1 & 2 & 3 & 4 & 5 & 6 & - \\
\hline
\end{tabular}

$v_{a}$, the number of individuals that were dominated by ' $a$ '.

FIGURE 1-A3: Dominance matrix 1 of vasectomised males on their own.

\section{Appendix 4}

\begin{tabular}{|lll|}
\hline $\begin{array}{l}\text { Number of individuals }(n) \\
\text { Vasectomised males }\end{array}$ & $(\mathbf{1 2} /(\boldsymbol{n} \wedge \mathbf{3}-\boldsymbol{n}))=$ & $\mathbf{7}$ \\
& Total wins $\left(v_{a}\right)$ & $\mathbf{0 . 0 3 5 7 1 4 2 8 6}$ \\
SH & 6 & $\left(\boldsymbol{v}_{a}-((\boldsymbol{n}-\mathbf{1}) / \mathbf{2})\right)^{\wedge} \mathbf{2}$ \\
KO & 5 & 9 \\
LU & 4 & 4 \\
KH & 3 & 1 \\
AS & 2 & 0 \\
NT & 1 & 1 \\
MG & 0 & 4 \\
& Sum $(\Sigma)=$ & 9 \\
& $h=$ & $\mathbf{2 8}$ \\
\hline
\end{tabular}

$v_{a}$, the number of individuals that were dominated by ' $a$ '.

FIGURE 1-A4: Application of Landau's formula of vasectomised males on their own using Appleby's (1983:600-608) method to test the strength of the hierarchies and De Vries' (1995:1375-1389) method to establish how close the results of both groups of males are to 1 . 


\section{Appendix 5}

\begin{tabular}{|lll|}
\hline $\begin{array}{l}\text { Number of individuals }(\boldsymbol{n}) \\
\text { Vasectomised and }\end{array}$ & $(\mathbf{1 2} /(\boldsymbol{n} \wedge \mathbf{3}-\boldsymbol{n}))$ & $\mathbf{1 1}$ \\
non-treaded males & Total wins $\left(\boldsymbol{v}_{\boldsymbol{a}}\right)$ & $\mathbf{0 . 0 0 9 0 9 0 9 0 9}$ \\
SH & 7 & $\left(\boldsymbol{v}_{\boldsymbol{a}}-((\boldsymbol{n}-\mathbf{1}) / \mathbf{2})\right)^{\wedge} \mathbf{2}$ \\
KO & 7 & 4 \\
LU & 5 & 4 \\
KH & 5 & 0 \\
AS & 3 & 0 \\
NT & 4 & 4 \\
MG & 2 & 1 \\
SM2 & 1 & 9 \\
SM3 & 1 & 16 \\
SM4 & 0 & 16 \\
UM & 0 & 25 \\
& Sum $(\Sigma)=$ & 25 \\
& $h=$ & 104 \\
\hline
\end{tabular}

$v_{a}$, the number of individuals that were dominated by ' $\mathrm{a}$ '.

FIGURE 1-A5: Application of Landau's formula of combined vasectomised and non-treated males using Appleby's (1983:600-608) method to test the strength of the hierarchies and De Vries' (1995:1375-1389) method to establish how close the results of both groups of males are to 1 .

\section{Appendix 6}

TABLE 1-A6: The association patterns of all study males indicating the mean percentage of observation time that each vasectomised and each non-treated male spent in mixed-sex groups with herd 1 and herd 2.

\begin{tabular}{lcc}
\hline $\begin{array}{l}\text { Vasectomised and non-treated } \\
\text { males }(\boldsymbol{n}=\mathbf{1 1})\end{array}$ & Herd 1 ( $\mathbf{\text { SEM}})$ & Herd 2 ( SEM) \\
\hline SH (vasectomised) & 94.15 & 5.85 \\
KO (vasectomised) & 93.45 & 6.55 \\
LU (vasectomised) & 18.50 & 81.50 \\
AS (vasectomised) & 68.07 & 31.93 \\
KH (vasectomised) & 96.69 & 3.31 \\
NT (vasectomised) & 94.84 & 5.16 \\
MG (vasectomised) & 82.90 & 17.10 \\
SM2 (non-treated) & 94.71 & 5.29 \\
SM3 (non-treated) & 99.16 & 0.84 \\
SM4 (non-treated) & 100.00 & 0.00 \\
UM (non-treated) & 7.68 & 92.32 \\
\hline
\end{tabular}

Note: $n=11$, the number of study males.

\pm SEM, the mean percentage of observation time spent. 